great deal of prudence. I consider it an error, too often perpetrated, to send to these stations habitual cases of colitis and I have more often than not seen patients suffer bad effects from them. They are only suited to cases where the dyspeptic or hepatic symptoms which exist at the same time as the intestinal phenomena are very pronounced; in that case a cure at Carlsbad or Vichy can alternate with a cure at Plombières or Châtelguyon.

Such are the three principal elements-a veritable therapeutic tripod-of the treatment of muco-membranous colitis. As may be seen, the means are exclusively hygienic, and what may properly be called drugs have not much to do with this treatment; they are almost always inefficacious, and sometimes even harmful, owing to the alcohol or other irritating substances that are often mixed with them. The physician is, however, obliged to fight against the painful phenomena that accompany colitis, for the patient asks for some relief. To this end belladonna in the form of suppositories should be used, or taken internally in the form of tincture or pills (one grain of the extract in five or six pills for every 24 hours), or frictions with an ointment containing mercury and belladonna can be given if a calming effect is desired, or with turpentine if a somewhat stimulating action is preferred. Very hot, large poultices, sprinkled with laudanum, placed on the abdomen also succeed very well; or in the same way applications of large compresses dipped in a very hot decoction of poppy-heads, covered over with impermeable taffeta and with strips of flannel, and kept on the entire night. Indian hemp calms the intestinal spasms very well. A good elastic belt is necessary to bold and to lift up the abdomen in patients who have noticeable enteroptosis. The physician should be chary of using drugs against the dyspeptic phenomena that accompany colitis, since generally these troubles are lessened as the state of the intestine improves; but, according to the case, a little hydrochloric acid may be used, or alkalies, absorbent inert powders (charcoal, chalk, magnesia), and nux vomica.

\section{ON THE REMOVAL OF THE GALL- BLADDER IN OPERATIONS FOR GALL-STONES.}

BY B. G. A. MOYNIHAN, M.S.LOND., F.R.C.S. ENG., SEMTOR ASSISTANT SURGEON TO THE LEEDS GENERAL INFIRMARY.

IN 1902 I read a paper entitled "A Series of Cases of Cholecystectomy" before the Yorkshire branch of the British Medical Association. I gave then the following indications for the performance of this operation: (1) in injuries of the gall-bladder, rupture, stab, or bullet wounds; (2) in gangrene of the gall-bladder; (3) in phlegmonous cholecystitis ; (4) in membranous cholecystitis ; (5) in chronic cholecystitis with dense thickening of the walls of the gall-bladder and cystic duct, with or without stenosis of the cystic duct, and in chronic cholecystitis when the gallbladder is shrivelled and puckered and universally adherent (in such cases it is no longer a receptacle for the bile); (6) in distension of the gall-bladder, hydrops or empyema, due to blockage of the cystic duct by calculus, stricture, growth, or external inflammatory deposits, or in cases of mucous fistula following operations for these conditions; (7) in cases of fistula between the gall-bladder or the cystic duct on the one hand and the stomach, duodenum, or colon on the other; (8) in multiple ulcerations of the gall-bladder or the cystic duct when gall stones have eroded their way through the walls into the liver, the duodenum, or other protective adherent masses ; and (9) in primary carcinoma of the gall-bladder. The result of my early cases was so satisfactory that 1 was led to put the operation to a more extended proof and as my experience increases I am tempted to ask whether it would not be the better treatment in all, or in nearly all, gall-stone operations to remove the gall-bladder entirely. The experience of every surgeon who bas worked extensively in this field of surgery is that the chief purpose and the main indication in any operation for gall-stones is the drainage of the gallbladder and bile-ducts. Of the validity of this experience there can be no question. We know that gall-stones are rendered troublesome by the cholecystitis or the cholangitis which they are the means of arousing. In many cases it is because of the inflammatory consequences that an operation is demanded. The essential part of any operation would therefore seem to be the drainage of the gall-bladder, prolonged for such a time as to allow a complete subsidence of the inflammatory process. Bat in the very great majority of cases the secondary inflammation has its origin and runs its course entirely within the gall. bladder; an infection of the hepatic or common ducts does not occur. In many cases, therefore, in removing the gallbladder we are doing away with the necessity for drainage by removing that structure the drainage of which seemed imperative. It is within the gall-bladder that the great majority of stones are formed; it is within the gall-bladder that the secondary inflammatory troubles break out and are, in the majority of cases, altogether limited. The removal of the gall-bladder, therefore, does away with the need for drainage. It renders less likely the formation of gallstones and it renders less likely the inflammatory consequences of their presence. If, however, the need for drainage is absolute it is possible, in fact quite easy, to drain the ducts after the gall-bladder has been removed. After the division of the cystic duct the stump of the duct may be slit up until the hepatic duct is reached or the cystic duct may be cut off flush with the common duct. It is then quite a simple matter to explore upwards and downwards with a spoon or with the finger to make certain that the ducts are clear of calculi and then to stiteh in, by a single catgut suture, a rubber drainage-tube. The presence of stones in the common duct does not debar one from removing the gall-bladder. In two cases I have removed stones from the ampulla of Vater by duodeno. choledochotomy and have then at once removed a chronically inflamed gall-bladder full of stones and, after dividing the cystic duct close to the common duct, have drained the latter with a rubber tube Both patients recovered without the slightest interruption The plea therefore that the need for drainage is opposed to the routine removal of the gall-bladder is answered by the fact that when the gall-bladder is removed the need for drainage does not often exist, as that need was due to the presence of the gall-bladder, and by the fact that if drainage of the ducts is desirable or necessary it can be carried cut without the smallest difficulty.

An examination into the recorded cases of carcinoma of the gall-bladder and of the adjacent portions of the liver shows that in approximately 95 per cent. (Siegert) the malignant change is due to the chronic irritation of gallstones. If the gall-bladder is removed there will, of course, be no chance of this malignant growth occurring. This is not, however, a point of much importance, for the cases of carcinoma are those in which no operation has been done by the time the surgeon sees the case the growth is already there. To make the argument for cholecystectomy a strong one from this point of view it would be necessary to show that malignant disease occurred after cholecystotomy, and so far as I know this has not been done. ${ }^{1}$ In the very great majority of operations for gall-stones there is ample evidence of long-standing inflammation in and about the gall-bladder The normal smoothness of the gall-bladder is gone, its deep blue colour is lost, and its supple walls have become thickened and tough. A glance at a gall-bladder during other abdominal operations will tell one in a moment whether stones are lying there. If the gall. bladder is blue it is healthy ; if opaque and grey or yellow there are, or there certainly have been, stones and a chronic inflammation aroused by them. In many cases, therefore, it will be concluded that cholecystectomy is the more desirable operation, but before its routine adoption is advocated it is necessary to show that the gall-bladder is useless and that its removal does not add any risk as compared with cholecystotomy. In the abstract one might be inclined to think that the loss of a bile reservoir capable of emptying on demand would be a serious matter to the individual or at the least a disability. The perfection of the mechanism of digestion so graphically told by Pawlow would seem to require that bile should be ejected in spurts, as it were, into the duodenum during digestion. $\mathrm{Ba}$ there is clinical experience in abundance to show that when all the bile is discharged from the body through an external biliary fistula, witbout a drop entering the intestine,

1 A case of malignant disease of the gall-bladier af ter cholecystotomy has been recently recorded by my colleague, Mr. R. Lawford Knagge. in THE LANCET of April 16th, p $1 \dot{C} 54$. 
the individual suffers no sign of disability of any kind. There is abundant evidence also, furnished by my own cases and by many others, to show that the removal of the gallbladder does not interfere with digestion, that the individual eats well, gains in weight, and to all appearance has the same duodenal digestion as an ordinary healthy individual. The gall-bladder, therefore, if not useless, can quite well be spared.

The removal of the gall-bladder does certainly not involve a greater risk than the operation of cholecystotomy. I have, in fact, in several cases been convinced that the removal of the gall-bladder made the operation simpler and shorter than it would have been if a multitude of small stones had been removed. By carrying out the operation in the manner described below it will be found a safe, speedy, and simple procedure. During the last two years I have inclined more and more to the performance of cholecystectomy, and after some hesitation and some trepidation, which experience has removed, I am strongly disposed to advocate the frequent, though not the invariable, adoption of this operation in preference to cholecystotomy. Its advantages are that the operation removes the chief source of the disease, that it thereby prevents in great measure a recurrence either of stones or of the inflammation which betokens their presence, that growths in the gall-bladder or adhesions around it are subsequently impossible, and finally, that the wound, if drainage is not required, may be caused to heal throughout by first intention. The gall-bladder is devoid of any strikingly useful purpose and its removal does not add to the danger of the operation. If drainage of the ducts is necessary it can be carried out quite satisfactorily. The presence of a stone in the common duct does not prohibit the operation, but drainage of the duct, after removal of the stone in the duct or in the ampulla, is necessary. The one disadvantage that may justly be urged against cholecystectomy is this : that if a late operation should become necessary-for stones can, and do, form in the hepatic and common duct-such an operation would be more difficult and almost certainly more dangerous. The possibility of a further operation being necessary cannot be denied but the likelihood of it is negligible. The list of conditions demanding cholecystectomy given at the beginning of this paper may therefore be considerably increased and made to include all cases, or almost all cases, of gall-stone disease requiring surgical treatment.

The operation of complete cholecystectomy is performed in the following manner. A vertical incision near the onter margin of the right rectus muscle is made and the muscle fibres are split. The usual length of this incision is five inches. If additional room be required it is best obtained by continuing the upper end of the incision along the costal margin upwards and inwards. All adhesions of the gall. bladder and ducts and liver having been cleared, the liver is rotated by gentle traction upon the gall-bladder until the cystic and common ducts are straightened and brought upon a level with the wound. By this manœurre the operation is rendered simpler and quicker. The gall-bladder may now be removed from before backwards or from behind forwards. Latterly I have preferred to divide the cystic duct and to secure the cystic artery before freeing the gall-bladder. By dragging upon the gall-bladder the cystic duct is made clearly discernible. Its peritoneal investment is divided and stripped up along the duct towards the hepatic and common ducts, so that a cuff of peritoneum is raised up from the cystic duct. The latter is divided after securing it with a catgut ligature and the cystic artery is also defined and secured. The peritoneal cuff is then turned over the divided end of the duct and sutured. If it is intended to drain the common duct no ligature on the cystic duct is necessary. The cystic duct is cut off at its junction with the hepatic and common ducts and into the opening that is left a rubber drainage-tube is stitched. The gall-bladder is then stripped up from behind forwards. The separation from the liver is readily effected by stripping up with the finger around which a thin strip of gauze is rolled. The peritoneum which passes from the liver to the gall bladder is cut with scissors about three-quarters of an inch away from the liver, so that after removal of the gallbladder the bared surface of the liver may be covered in by peritoneum. There is occasionally some bleeding from the denuded liver. This is readily checked by a suture or by the firm pressure of a hot swab or sponge. If the common duct is drained it is well to put in two other drains, one to the inner side of the duct towards the duodenum and one to the outer side towards the kidney pouch. These drains, whether of gauze or of rubber tubing, should be stitched in position by one or more sutures of catgut and they are left in for from eight to ten days. At the end of this time their removal is quite easy. It is necessary to stitch them in position in order to prevent them being moved away within a few hours on account of the constant movements of the liver during respiration. Leeds.

\section{NOTE ON THE CAUSES OF COUGH IN CHILDREN.}

By ARTHUR W. FULLER, M.D. EDIN.

RESIDENT MEDICAL OFFICER TO THE ROYAL WATERLOO HOSPITAL FOR CHILDREN AND WOMEN, LONDON.

THERE are many cases of ill-health occurring amongst children in which, although cough is a persistent symptom, the physician is unable to detect any abnormal physical signs in the chest and the usual expectorants are exhibited in vain. There is frequently vomiting in these cases and wasting and weakness may become so marked that life may be despaired of. The severer forms have been often called "consumption" or "decline," while the milder have received the names " bronchitis" or "bronchial catarrh," whereas, as I have indicated, neither the lungs nor the bronchi are at fault. Those cases where the cough is accompanied by spasm and a consequent "whoop" are put down at once as whooping-cough, may be treated as such for months, and frequently serious chest trouble ensues. Their non-infectious nature should be sufficient to guard against this error. In the large majority of these cases it is to the back of the throat, the tonsils, the fauces, and the pharynx that we must go for the fons et origo of the condition. A very slight degree of pharyngitis, of tonsillitis, or of adenoid growths in the naso-pharynx may produce cough in a child the reflex activity of whose nervous system is high. I desire to point out the frequency of the occurrence of one or other of these conditions in children suffering from cough and to recommend that the throat at least should be examined in every rase.

Adenoid cough has beeen recognised for some time although in the existing text-books on diseases of children it scarcely receives the place it deserves and in some it is not even mentioned. Of 621 consecutive cases of cough which I have treated during the past two years, most of which were supposed by the mothers to be whooping covgh and were brought to the Royal Waterloo Hospital as such, no less than 371 of the patients were suffering from tonsillitis, pharyngitis, or chronic enlargement of the tonsils, or from post-nasal adenoid growths in a greater or less degree, and most of them lost their cough entirely when the throat was put in a satisfactory condition. This proportion is high and probably is not applicable to many places outside London, or even to the healthier parts of London, but amongst the children living in the poorer districts of this city inflammatory conditions of the pharynx, tonsillitis, and adenoids prevail to an enormous extent, and it is a serious question for the Commission appointed to inquire into the causes of the alleged physical degeneration of our race what part enlarged tonsils and the presence of adenoids contribute to that result. At the Infirmary for Children in Liverpool the proportion of these cases was not nearly so high, due, in my opinion, to the different atmospheric conditions prevailing. The heavy, foggy atmosphere of London, holding, as it does, much organic matter and micro-organisms in suspension, especially in low-lying and overcrowded districts, would appear not only to initiate but to keep up a chronic irritation of the mucous membrane of the throat and pharynx, aided by an insufficient amount of vigorous exercises and the consequent enfeeblement of the circulation and defective development of the breathing apparatus. The great desiderata from this point of view are more and larger open spaces where children may be allowed to play and realise that they are really children (and not, as it were, pocket editions of men and women), where they can flush out their air passages with an approach, at any rate, to pure air and thus counteract to some extent the pernicious 6 ffects of the atmosphere in which they must perforce live and work. 